\title{
Impact of Innovative Teaching Programme on Knowledge and Skill regarding Basic Cardiac Life Support among Students
}

\author{
${ }^{*}$ Ms.Feba Sam, ${ }^{* *}$ Dr. Renuka K\& ***Nandhini.S
}

\section{Abstract:}

Objectives: To evaluate the impact of innovative teaching programme on knowledge and skill regarding basic cardiac life support. ${ }^{2}$ Method: quasi-experimental research design with a quantitative research approach was undertaken on 30 students. Results: The findings revealed that innovative teaching programme on knowledge and skill regarding basic cardiac life support was effective as the mean was 3.87 with standard deviation of 2.11 in pretest but in the post test the mean was 15.73 with standard deviation of 1.01 which was found statistically highly significant at p<0.001 level. Conclusion: That innovative teaching programme was found highly significant in enhancing the knowledge and skills of students on basic life support measures. ${ }^{3}$

Key words: Evaluate, Impact, Innovative Teaching, BLS

\section{INTRODUCTION}

Emergency, fear, disaster, gloom and despair, these words and thousands like them are repeated over and over every day, somewhere by somebody. What is to be done? For a person with a reasonable knowledge on the basics of first aid, there is usually a clear-cut course to follow. There is no need to be panic. There are some techniques that help a person to be saved from death, one of these techniques is the Cardio Pulmonary Resuscitation. Cardio Pulmonary Resuscitation (CPR) is an emergency first aid protocol for an unconscious person on whom neither breathing nor pulse can be detected. ${ }^{2}$ The medical term for a patient whose heart has stopped is cardiac arrest, in which case CPR is used. If the patient still has pulse, but is not breathing, this is called respiratory arrest and rescue breathing is used. ${ }^{8}$

\section{OBJECTIVES:}

- To assess the level of knowledge and skill on basic cardiac life support among Higher Secondary School students during pretest

- To evaluate the impact of innovative teaching programme on knowledge and skill regarding basic cardiac life support measures among Higher Secondary School students during posttest.

- To find out the association between the pretest knowledge and skill wih the selected demographic variables.

\section{HYPOTHESES:}

$\mathbf{H}_{01}$-There is no significant difference in the pre and posttest level of knowledge and skill on basic cardiac life support among higher secondary school students. 
$\mathbf{H}_{02}$-There is no significant impact of innovative teaching programme on knowledge and skill regarding basic cardiac life support among higher secondary school students during posttest.

$\mathbf{H}_{03}$-There is no association between the pretest level of knowledge and selected demographic variables.

\section{METHODOLOGY:}

Research approach used for the study was Quantitative Research Approach and the Research design was Quasi-Experimental Research design. The study was conducted in V O Chidambaram Govt Boys Higher Secondary School situated in Mission street in Puducherry.
The Sample size was 30. The samples were selected based on the inclusion criteria; Simple Random Sampling Technique was used to select the samples. Pre-test was done to assess the knowledge and skill regarding basic cardiac life support by knowledge questionnaire. After pre-test innovative teaching programme on knowledge and skill regarding Basic Cardiac Life Support was provided through lecture method.Post-test was conducted after the gap of 7 days of Structured Teaching Programme. The data were analyzed by using descriptive and inferential statistics like frequency, percentage, mean, standard deviation, paired T-Test and ChiSquare test.

\section{DATA ANALYSIS}

Table 1 Mean, Standard Deviation, Paired ' $t$ ' Test And $p$ Value of Pre And Post Test Scores on Knowledge regarding Basic Life Support

$N=30$

\begin{tabular}{|c|c|c|c|c|}
\hline Knowledge & Mean & SD (\%) & $\begin{array}{c}\text { Paired 't' test } \\
\text { (df) }\end{array}$ & P value \\
\hline Pretest of knowledge & 3.87 & 2.11 & & \\
\cline { 1 - 3 } Post test of knowledge & 15.73 & 1.01 & $.000^{*}$ \\
\hline
\end{tabular}

$S D$-Standard Deviation.

${ }^{*}$ Highly Statistically Significant $P<0.001$

The knowledge mean of 3.87 with the SD of 2.11 in the pretest was increased to 15.73 with the SD of 1.01 in the post test after innovative teaching programme. Statistically innovative teaching programme was found highly significant at $p$ value $<0.001$ in enhancing the knowledge of students on basic life support measures.

\section{Mean, Standard Deviation, Paired ' $t$ ' Test and $p$ value of Pre and Post Test Scores on Skill regarding Basic Life Support.}

\begin{tabular}{|c|c|c|c|c|}
\hline Skill & Mean & SD (\%) & $\begin{array}{c}\text { Paired ' } \mathbf{~} \text { ' } \\
\text { test (df) }\end{array}$ & P value \\
\cline { 1 - 3 } Pretest & 2.03 & 1.43 & \multirow{2}{*}{29} & \multirow{2}{*}{$.000^{* * *}$} \\
\cline { 1 - 3 } Posttest & 54.06 & 1.617 & & \\
\hline
\end{tabular}

$S D$-Standard Deviation. $\quad{ }^{* * *}$ Highly statistically significant $P<0.001$ 
The skill mean of 2.03 with the SD of 1.43 in the pretest was increased to 54.06 with the SD of 1.617 in posttest after innovative teaching programme. Statistically innovative teaching programme was found highly significant at $p$ value less than 0.001 in enhancing the skill of students on basic life support measures.

\section{Association between Pretest Skill on basic life support and demographic variables.}

In pretest all the students $30(100 \%)$ are coming under same level of skill. Thus there is no chi square value available and there is no significant association with the demographic variables.

\section{RECOMMENDATIONS:}

$>$ The similar study could be done using experimental and control group

$>$ The comparative study can be done among innovative teaching and any other conventional method of teaching.

\section{CONCLUSION:}

The study reveals that the innovative teaching programme was found effective in improving the knowledge and skill on basic life support among higher secondary school students. The knowledge of the BLS helps to save the life of the casuality in emergency conditions, so we can promote the use of innovative teaching method to improve the knowledge and skill regarding BLS among general public.

\section{REFERENCES:}

1. Lewis,et al. medical surgical nursing assessment and management of clinical problems. Mosby publications; $7^{\text {th }}$ edition.2009.

2. Susan.L.Woods, et al. Text Book of Cardiac Nursing. Lippincott Williams and Wilkins Publishers; $6^{\text {th }}$ Edition:2010.

3. Barbara Kozier, et al. Fundamentals of Nursing. Pearson Education Publication;7thEdition.1999.

4. Black, M. Joyce. Medical Surgical Nursing. W.B. Sanders Company; India: $3^{\text {rd }}$ edition. 1999.

5. Rajaram $\mathrm{R}$, et al. Survival after cardiopulmonary resuscitation in an urban Indian hospital. Natl Med J India; 1999 .

6. Bihari $\mathrm{S}$ et al. Prolonged retention of awareness during cardiopulmonary resuscitation for asystolic cardiac arrest. Neurocrit Care; 2008.

7. PhilpsWilma.j,Shafers, et al. medical surgical. Philips Long Wood Publications;7thEdition;1998.

8. Patrecia A Potter, Annie Griffin Perry. Fundamentals of Nursing. Mosby Publications;16th Edition, 2006.

9. Suzanne C Smeltzer, Brenda Bare, Brunner and Suddarth's Text book of medical surgical nursing. Lippinkott Williams \& Wilkins Publishers; $10^{\text {th }}$ edition, 2004.

10. Linda S Williams, Paula D Hopper, Understanding Medical Surgical Nursing.Jaypee Publishers; $3^{\text {rd }}$ Edition: 2006. 